\title{
Reply to Letter to the Editor "Staple Line Reinforcement in Laparoscopic Sleeve Gastrectomy: Experience in 1023 Consecutive Cases" Obesity Surgery June 2017 Issue 6: 1474-80 by Sepúlveda et al.
}

\author{
Matías Sepúlveda $^{1,2}$ (D) Cristián Astorga $^{1} \cdot$ Juan P. Hermosilla $^{1,2} \cdot$ Munir Alamo $^{3}$
}

Published online: 7 July 2017

(C) Springer Science+Business Media, LLC 2017

We greatly appreciate the interest and insights about our article regarding staple line reinforcement in sleeve gastrectomy.

We wanted to present these results because we believe that imbricating (Lembert's technique) oversewing is a low-cost tool, that when properly used, can help prevent leakage in the staple line, one of the most feared and expensive complications. Since our study was accepted, we have initiated a prospective cohort by oversewing only the proximal third, in order to avoid leaks, and controlling intraoperative bleeding either with clips or by finishing the suture until the antrum. To date, this series comprehends 66 patients: only one of them presented abdominal pain on the seventh day postoperatively, with a positive tomography for minor paragastric hematoma. He was treated only with analgesics without readmission.
We also have a fellowship program, and we totally agree that intracorporeal suturing is a great advantage and a necessary skill in any advanced laparoscopic surgeon.

We think that randomized controlled trials comparing transfixiating versus imbricating suture could be of interest because, according to our experience and the literature, leaks are mainly because of ischemia of the gastric segment where the last staple fire is made, so perhaps through and through stiches might not prevent them as well as the Lembert's technique.

\section{Compliance with Ethical Standards}

Conflict of Interest The authors declare that they have no conflict of interest.
Matías Sepúlveda

drmsepulveda@gmail.com

Cristián Astorga

astorgalarrondo@gmail.com

Juan P. Hermosilla

drjphermosilla@gmail.com

Munir Alamo

munir.alamo@gmail.com

1 Department of Bariatric and Metabolic Surgery, Hospital Dipreca, Vital Apoquindo 1200, Las Condes, Santiago, Chile

2 School of Medicine, Universidad Diego Portales, Ejército 233, Santiago, Chile

3 Department of Surgery, Hospital El Carmen, Camino A Rinconada 1201, Maipú, Santiago, Chile 